\title{
Approach-avoidance conflict in preweanling rats: A developmental study
}

\author{
ALEXIS C. COLLIER, JOELLE MAST, DONALD R. MEYER, \\ and CARRIE-ELLEN JACOBS \\ The Ohio State University, Columbus, Ohio 43212
}

\begin{abstract}
Ten- and 15-day-old rat pups were trained with two procedures to approach an anesthetized mother, and then were punished for approaching. Both ages of subjects exhibited increased latencies to reapproach the mother, indicating passive inhibitions, but only the older pups retreated. All but one of the younger pups eventually reached the mother within $3 \mathrm{~min}$ after the punishment, while only half of the older pups did so. In a second experiment examining the development of locomotor avoidance reactions, 5- to 20-day-old rats were shocked without the mother present. Fifteen- and 20-day-old rats significantly decreased their activity patterns in reaction to shock and spent significantly less time in the shock area than either of the younger aged pups. These results suggest that flight reactions are components of a rat's defensive repertoire that appear very rapidly between 10 and 15 days of age.
\end{abstract}

Although information on the effects of punishment in very young organisms is limited (Walters \& Grusec, 1977), we do have a certain amount of information available with respect to the behaviors of preweanling rats (younger than 20 days) in step-through and step-down passive avoidance situations (Riccio, Rohrbaugh, \& Hodges, 1968; Riccio \& Schulenburg, 1969). In such situations, very young rats are slower to reach a high criterion of performance than weanling or older subjects. What has not been clear is whether the results imply that young animals are slower to learn aversive responses, or whether they do learn the contingencies of punishments, but nonetheless fail to avoid because of their innate reactions to punishing events (Campbell, Riccio, \& Rohrbaugh, 1971). The question is further confounded in that the data on preweanling rats have been restricted to the examination of punishment on only untrained, highly probable responses (e.g., crossing to the dark side of an alley or stepping off a platform).

The limitation to untrained response assessment has been due, in part, to a paucity of adequate techniques for studying aversively controlled, as well as appetitively controlled, behaviors in preweanling subjects. However, recent evidence (e.g., Amsel, Burdette, \& Letz, 1976; Kenny \& Blass, 1977) indicates that very young rats can be trained to approach an anesthetized mother for dry suckling as a reward. By punishing such a learned approach response, it would now be possible to examine further the characteristics of aversive stimulation during the very early

Requests for reprints should be sent to the first author, Laboratory of Comparative and Physiological Psychology, The Ohio State University, 1314 Kinnear Road, Columbus, Ohio 43212. Portions of this research were supported by PHS Grant 5 T32 MH14608-02 to The Ohio State University while Joelle Mast and Carrie-Ellen Jacobs were NRS Fellows. stages of development. Therefore, a major concern in the present investigations was to study the effects of punishment on young pups' behaviors in approachavoidance conflict situations. Also, we were interested in examining the unlearned responses of preweanling rats to shock alone when the approach conflict element was removed.

\section{EXPERIMENT 1}

Experiment 1 was designed to assess the punishment of an appetitive habit early in development by shocking neonatal rat pups for running to an anesthetized mother for reward. The procedures we used paralleled those used by Bresnahan, Meyer, Baldwin, and Meyer (1976) for assessing avoidance deficits in septally lesioned adult rats. In addition to the approach alley, the pups were provided with an alternative alley on test trials to allow them to run away from the shock source. Thus, pups could perform the passive avoidance task and avoid shock either by passively inhibiting the approach response and remaining immobile in the startbox after the shock or by actively moving into a neutral alley away from shock. In this way, the account of simple unlearned increases in activity as one possible explanation for the previously reported passive avoidance deficits in young rats (Campbell et al., 1971) could better be determined as some active locomotor responses could result in avoidance behavior. Also, both a simple approach and a choice procedure were used for the initial approach training to see whether or not exposure to the alley opposite that containing the mother would alter the pups' behavior in the conflict task.

\section{Method}

Subjects. The subjects were 26 Sprague-Dawley rat pups. Eight 
pups were taken from two litters and 10 pups from one litter born in the laboratory's colony. All of the litters had been trimmed to 10 pups when the animals were 3 days of age. Half of the experimental animals from each of the litters were selected randomly and tested at 10 days (10d) of age, while half were tested at 15 days ( $15 \mathrm{~d}$ ) of age.

Apparatus. The apparatus was a scaled-down version of the Maher, Elder, and Noblin (1962) apparatus, and consisted of a startbox and alleys that ran in opposite directions to two goalboxes of the same size as the startbox $(15.24 \times 15.24 \mathrm{~cm})$. The alleys were $40.6 \mathrm{~cm}$ long and $6.35 \mathrm{~cm}$ wide. The walls of the alleys and the goalboxes were $15.24 \mathrm{~cm}$ high. One alley and goalbox was painted black, the other alley and goalbox was painted white, and the startbox was gray. Grids for delivering shocks were located directly in front of both of the two goalboxes and were flush with the floor. A standard Lafayette Model A-615B shocker was used to deliver shock at predetermined intensities.

Procedure. The pups were separated from their mothers prior to training and were kept in a thermoregulated nest of shavings. The $10 \mathrm{~d}$ and $15 \mathrm{~d}$ subjects were deprived of their mothers for 12 and $16 \mathrm{~h}$, respectively, since these deprivation periods have been found (Collier, Note 1) to result in approximately equal percentages of body weight loss (between $4 \%$ and $6 \%$ ). Each pup then was trained to approach its mother, which had been placed in one of the two goalboxes after having been anesthetized with chloropent $(2 \mathrm{ml} / \mathrm{kg}$ IP), a general anesthetic which blocks milk release.

Two procedures were used in the initial approach training. In the straight-alley (SA) procedure, the alternative alley was blocked at the startbox. Initially, each pup was placed beside its mother and allowed to attach to a nipple for $15 \mathrm{sec}$. For shaping purposes, it was then placed in the startbox and gently pushed down the alley toward its mother and allowed to attach once again. Then, with trials spaced at $5 \mathrm{sec}$, the pup was reinforced for running to its mother with 15 -sec nipple attachments.

With the choice-alley (CA) methodology, the procedures were the same as with the SA procedure, except that the subjects were trained initially in a choice situation. Thus, each pup in the CA procedure was given explicit experience with the alley opposite to that containing the mother. For CA training, the floor of one alley was left uncovered, and the other was covered with coarse sandpaper. The startbox was covered with fine sandpaper. After an initial attachment to the mother, each pup was placed in the startbox and pushed toward the goalbox, where it was permitted to attach to the mother's nipples for $15 \mathrm{sec}$. On the following trial, the pup was pushed through the other alley and kept in its empty goalbox for $15 \mathrm{sec}$. For additional shaping, when the pup entered either one of the alleys on the next two trials, the entrance to that alley was blocked by a door in the startbox to prevent retracing. Thereafter, both alleys were always open and each pup was trained to approach its mother as in the SA procedure. Eight pups at each age were trained with the SA procedure, and five pups at each age with the CA procedure.

Times to leave the startbox (startbox latency) and to reach the mother (total time) were measured to the nearest . $1 \mathrm{sec}$ with a stop clock. Approach training was continued until the pup left the startbox within $15 \mathrm{sec}$ and reached the mother on $8 / 10$ trials. A pup was considered to be out of the startbox if at least three paws were in the alley. After reaching this criterion, designated the CT trial, the pup was punished on the next trial for approaching its mother by a $3-\mathrm{sec} .75-\mathrm{mA}$ footshock from the floor grid located in front of the mother. Following this .75-mA weak-shock (WS) trial, the pup was punished on the next trial for approaching its mother by a 3-sec 1.4-mA footshock. The second punishment trial was designated the strong-shock (SS) trial. Then the shock source was turned off, and in the SA procedure the door that had blocked the opposite alley was removed. The pup was put back in the startbox and its positions on the last trial (LT) were recorded every $5 \mathrm{sec}$ until it reached its mother, or for a maximum period of $3 \mathrm{~min}$. The apparatus was cleaned after each pup was studied, and the goalboxes were counterbalanced for approach.

\section{Results}

The $10 \mathrm{~d}$ subjects in both procedures required a median of 15 trials to reach criterion. The median number of trials for $15 \mathrm{~d}$ SA and CA subjects were 10 and 13 trials, respectively. In both investigations, $10 \mathrm{~d}$ subjects were significantly slower to reach criterion (Kruskal-Wallis ANOVA, ps $<.01$ ). However, the methods were effective for training all subjects, and the findings were consistent with outcomes obtained in several other recent studies (Amsel et al., 1976; Kenny \& Blass, 1977).

Given the disparity and nonproportionality of the group sizes, nonparametric tests were used in comparing SA with CA training procedures (Myers, 1972). There were no significant effects of SA vs. CA training for either age on times for subjects to leave the startbox or total time to reach mother on Trials CT, WS, SS, and LT (Mann-Whitney Us, all ps > .25, alpha-controlled experimentwise). Hence, the findings from the two experiments have been combined with $\mathrm{n}=13 /$ age for additional comparisons. Latency measures were then logarithmically transformed, as such measures are typically logarithmically distributed, thus allowing for the assessment of both age and trials effects in a single parametric statistical design. For more meaningful inspection of the data, median latencies of the nontransformed data rather than the log transforms themselves are presented. Table 1 shows these median latencies for startbox exit and total time required for subjects to reach mother on Trials CT, WS, SS, and LT. Time spent in the alley can be approximated from total time which includes both startbox and alley section measures.

Mixed ANOVAs with one between (age) and one within (trials) factor were performed on the transformed latency data. Results for both measures showed a highly significant main effect for Trials $\left[\mathrm{F}_{\text {startbox }}(3,72)=22.29, \mathrm{p}<.001 ; \mathrm{F}_{\text {total time }}(3,72)\right.$ $=9.08, \mathrm{p}<.001]$. Newman-Keuls tests showed that there was a significant increase in startbox exit and

Table 1

Median Startbox Latency and Total Time (in Seconds) for Combined Choice and Straight Alley Procedures

\begin{tabular}{lrrrrr}
\hline & & \multicolumn{4}{c}{ Trial } \\
\cline { 3 - 6 } & Age* & \multicolumn{1}{c}{ CT } & \multicolumn{1}{c}{ WS } & \multicolumn{1}{c}{ SS } & \multicolumn{1}{c}{ LT } \\
\hline \multirow{2}{*}{ Startbox Latency } & 10 & 7.65 & 8.09 & 17.51 & 24.91 \\
& 15 & 6.00 & 6.57 & 15.00 & 32.61 \\
Total Time & 10 & 12.20 & 15.00 & 40.00 & 40.00 \\
& 15 & 8.80 & 22.70 & 25.20 & 160.00 \\
\hline
\end{tabular}

*In days. 
total time to reach mother following shock (ps $<.05$ ). ${ }^{1}$ Latencies to leave the startbox increased significantly after Trial WS, the trial on which the first shock was given. Latencies were significantly longer on Trials SS and LT than on WS (ps $<.05$ ). Following the second shock trial, SS, startbox latencies again increased, with times on Trial LT being significantly longer than SS $(p<.05)$. Total time measures on Trial WS reflect both pre- and postshock effects since the first punishment was delivered from the grid in front of the mother just prior to nipple attachment. Total time, as with startbox time, increased significantly following a single shock: WS, SS, and LT were all significantly longer than Trial CT (ps<.05). Total time measures on Trial SS reflect both preand postsecond shock effects, since shock was again delivered just prior to attachment. After the second shock trial, total time did not increase significantly from Trial WS to Trial SS. The cumulative effects of both shocks on Trial LT, however, are indicated by significantly longer latencies for total time on Trial LT than on either Trial WS or Trial SS ( $\mathrm{ps}<.05$ ).

Although neither the Age nor the Age by Trials interaction effects approached significance, it is apparent from Table 1 that for $10 \mathrm{~d}$ subjects, total time increased very little on Trial WS. This was due to the fact that $10 \mathrm{~d}$ pups' invariable reactions to the first shock were to jump from the grid to the mother, whereas $15 \mathrm{~d}$ subjects would jump back into the alley and then reapproach the mother. A comparable effect to that seen in 10d pups' reactions to the weak shock is apparent in $15 \mathrm{~d}$ subjects after the stronger shock. Total time increased very little from Trial WS to Trial SS for the older pups, with startbox latencies accounting for most of the total time on Trial SS. The cumulative effects of both shocks, however, resulted in a second substantial increase in total time latencies for $15 \mathrm{~d}$ pups, as shown by measurements on the last trial. Similar effects have previously been reported with older subjects where two shocks are often necessary for the passive avoidance response to be seen (e.g., Riccio \& Schulenburg, 1969). After two punishment trials, 12 of the $1310 \mathrm{~d}$ subjects failed in the passive avoidance task in the sense that they still reached the mother within $3 \mathrm{~min}$. The other pup's position when its time ran out was in the alley segment immediately adjacent to the goalbox. Six of the $1315 \mathrm{~d}$ subjects passively avoided the mother in the sense that they failed to attach to a nipple within $3 \mathrm{~min}$ on LT.

Figure 1 shows pups' alley positions on LT for both the SA and CA training procedures. The similarity of the behavioral patterns with both procedures is clearly illustrated, yet the analysis of $10 \mathrm{~d}$ and $15 \mathrm{~d}$ pups' activity patterns reveals a striking difference not observed in the temporal measures alone. The older pups, after having left the startbox, approached

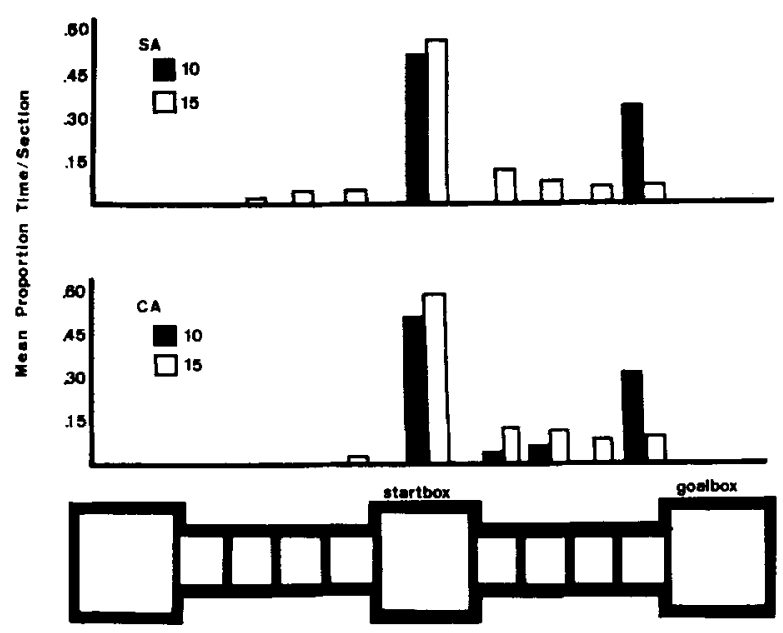

Figure 1. Mean proportion time (seconds) per alley section on the last trial for 10 - and 15-day-old rats trained with the straight-alley and choice-alley procedure.

and then retreated from the goalbox, thus distributing their times in several segments of the alley. In contrast, the younger pups, after having left the startbox, approached the mother and halted in the alley segment just in front of the goalbox. No 10d subject retreated. To score this behavior, the number of paths a subject took was counted. Paths were defined as the number of changes in direction plus the initial path. A score of 0 was given if a subject never left the startbox. The $15 \mathrm{~d}$ subjects took a mean of 3.34 $\pm .68 \mathrm{SE}$ paths, while the $10 \mathrm{~d}$ subjects took $1.00 \pm$ .00 SE paths.

\section{EXPERIMENT 2}

Experiment 2 was designed to examine reactions to shock when the conflict element was removed. As such, the locus of the shock was moved to the center of the apparatus, the mother was no longer present, and flight behaviors from the shock area were investigated. In addition, the behaviors of very young and near weanling rats were studied.

\section{Method}

Subjects. The subjects were 40 5-day-old (5d), 10d, 15d, and $20 \mathrm{~d}$ Sprague-Dawley rats taken from five litters born in the laboratory's colony. The litters were culled to 9 pups each at 3 days of age. Two pups from each litter were selected randomly to be tested at one of the four age conditions. The deaths of two pups in one of the litters necessitated using an extra pup from a subsequent litter to fill out the age conditions. The extra pup was assigned to the $20 \mathrm{~d}$ group, resulting in $n=10$ for each of the four age conditions. The subjects were nondeprived at the time of testing.

Apparatus. The apparatus was the same as the one described in the previous experiment, except that the grids were removed from their placements in front of the two goalboxes and a single floor grid was placed in the center startbox section of the apparatus.

Procedure. Initially, each pup was removed from the mother 
and placed in the startbox. It then was pushed gently down one alley, returned to the startbox, and then pushed down the other alley. After a 30-sec intertrial interval (ITI), each pup was given four more trials with its behavior and alley position observed at 5-sec intervals for a 3-min period on each of the trials. A 30-sec ITI always was given between trials. On the first trial (FT), the pup was placed on the shock grid in the middle of the apparatus and its position was recorded for $3 \mathrm{~min}$. A pup was considered to be in a particular alley segment if at least three feet were within the segment. If two feet were in each of two adjacent segments, an intermediate score was given, and time spent in the intermediate position was divided between the two adjacent segments. No shock was delivered on the first baseline trial. The next three trials were designed to deliver two punishment trials followed by an observation trial in a manner similar to the last three trials of Experiment 1. On the WS trial, the pup was placed on the shock grid in the middle of the startbox and a $3-\mathrm{sec} .75-\mathrm{mA}$ footshock was immediately delivered. On the SS trial after that, the subject was given a $3-\mathrm{sec} 1.4-\mathrm{mA}$ footshock. On the last trial, LT, no shock was delivered. No barriers were used on any of the trials, and subjects could escape shock on WS and SS trials. Escape latencies were measured to the nearest 5 -sec interval in the same manner as latencies to leave the shock area on FT and LT trials.

\section{Results}

Since the time measurements were taken to the nearest 5 -sec interval in the second experiment and therefore are not continuous data, latency scores were not transformed to obtain logarithmically distributed scores as in Experiment 1. Also, the addition of $5 \mathrm{~d}$ and $20 \mathrm{~d}$ subjects resulted in heterogeneity of variance across the groups. Nonparametric analyses were thus performed on the nontransformed data.

Table 2 shows the median latency to leave the startbox to the nearest $5 \mathrm{sec}$ on each of the five trials. The data indicate a marked developmental trend toward an increase with age in initial tendencies to leave the start area on the preshock baseline measure, and an increase with age in later trial tendencies to escape the shock area after receiving shock. Five-day and $20 \mathrm{~d}$ subjects showed the least change across trials. The typical $5 \mathrm{~d}$ subject never left the startbox regardless of whether it received shock or not, while the typical $20 \mathrm{~d}$ subject always left the startbox area within $5 \mathrm{sec}$ of being placed in the apparatus. The $10 \mathrm{~d}$ and $15 \mathrm{~d}$ subjects, however, displayed an interesting transition between the $5 \mathrm{~d}$ and $20 \mathrm{~d}$ extremes where shock was observed to modulate performance.

Table 2

Median Latency to Leave the Startbox to the Nearest 5-Sec Interval on No-Shock and Shock Trials

\begin{tabular}{rrrrr}
\hline & \multicolumn{4}{c}{ Trial } \\
\cline { 2 - 5 } Age* & FT & WS & SS & LT \\
\hline 5 & 180.0 & 180.0 & 180.0 & 180.0 \\
10 & 110.0 & 5.0 & 5.0 & 25.0 \\
15 & 10.0 & 20.0 & 10.0 & 10.0 \\
20 & 5.0 & 5.0 & 5.0 & 5.0 \\
\hline
\end{tabular}

*In days.
Table 3

Mean Number of Paths Taken on No-Shock and Shock Trials

\begin{tabular}{rrrrr} 
& \multicolumn{4}{c}{ Trial } \\
\cline { 2 - 5 } Age* & FT & WS & SS & LT \\
\hline 5 & .3 & .1 & .2 & .1 \\
10 & 1.5 & 2.4 & 3.0 & 1.6 \\
15 & 5.1 & 2.3 & 1.9 & 1.7 \\
20 & 3.6 & 1.2 & 1.2 & 1.0 \\
\hline
\end{tabular}

*In days.

Wilcoxon pairwise comparisons showed a significant decrease in the latency for $10 \mathrm{~d}$ subjects to leave the start area from the FT baseline measure to the WS trial $(p<.01)$, and a significant increase in the latency for $15 \mathrm{~d}$ subjects, where more freezing behaviors were observed $(\mathrm{p}<.05)$.

A trend similar to the escape latency data is apparent in the path data for the different aged subjects and is shown in Table 3. Again, there is a clear developmental trend toward flight behaviors from preshock to shock trials. Five-day-old pups never left the shock area even on shock trials, while $20 \mathrm{~d}$ pups were initially more exploratory, taking a mean number of $\mathbf{3 . 6}$ paths. Following shock, there was a significant decrease in the number of paths taken by $20 \mathrm{~d}$ subjects from the FT to the WS trial (Wilcoxon, $p<.05$ ). These older subjects were observed to quickly dart toward the end of the apparatus away from the shock box area and remain there for the full 3-min observation period.

The trend toward flight away from the shock area appears to occur between the $10 \mathrm{~d}$ and $15 \mathrm{~d}$ period where an age-dependent bidirectional effect of shock is found. Initially, 15d pups took the most paths, a finding consistent with other outcomes showing an increased number of cage crossings in $15 \mathrm{~d}$ rats compared to younger and older subjects (Campbell \& Raskin, 1978). Following the first shock, the number of paths taken by $15 \mathrm{~d}$ subjects decreased from preshock baseline measures, (Wilcoxon, $p<.01$ ), whereas the number of paths taken by $10 \mathrm{~d}$ subjects increased, although not significantly so.

Figure 2 shows pups' alley positions on the last trial. Five-day-old pups rarely left the shock area, spending $93 \%$ of their time in the startbox segment. Twenty-day-old pups, however, showed a clearly developed flight reaction away from the shock area and spent $100 \%$ of their time in one of the goalboxes located at the far ends of the alley. With the position data, as with the latency and path data, the tendency toward flight was found to emerge between 10 and 15 days of age. Fifteen-day-old pups spent significantly less of their time in the shock box area than did the $10 \mathrm{~d}$ pups (Mann-Whitney $U=15.5, \mathrm{p}<.02$ ), and a larger proportion of their time, although not significantly so, in or near the goalbox areas away from 


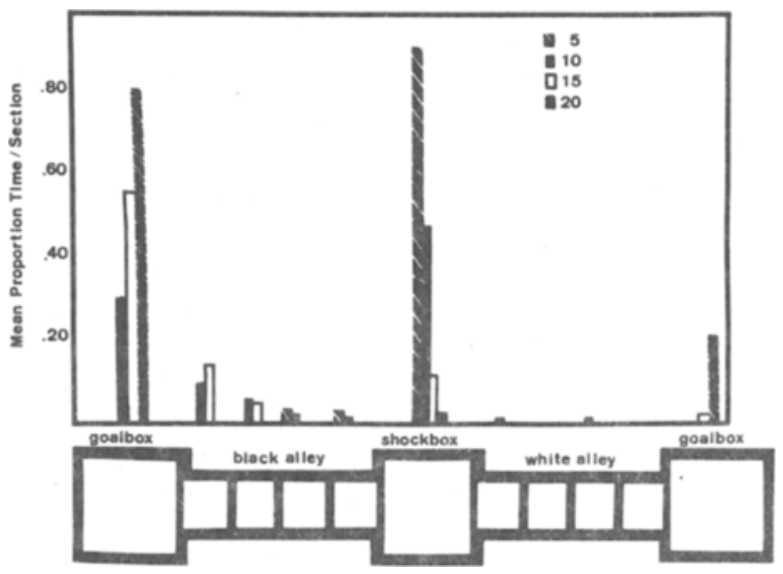

Figure 2. Mean proportion time (seconds) per alley section on the last trial for rats at various ages.

shock. Notably, for those subjects that left the shock area, there was a clear preference for the black side of the alley, even by 10 days of age.

\section{DISCUSSION}

The findings of Experiment 1 first of all confirm the results of previous studies (Amsel et al., 1976; Kenny \& Blass, 1977) that very young rat pups can readily be trained to approach an anesthetized mother for reward and learn a choice discrimination. Furthermore, young pups were found to learn the approach response in an alley substantially longer than those used in previous reports.

The results also show that a single weak shock is sufficient to establish an avoidance response in animals as young as 10 days of age. On the trials following shock, there was a significant increase in startbox latencies which cannot be accounted for by any debilitating effects of the shock alone. Such a supposition is contradicted by the fact that the pups ran very quickly once they left the startbox, and that they were observed to halt with great precision in the alley segment directly in front of the shock grid before continuing on to the mother. Such behavior indicates that they were neither disoriented nor debilitated by the punishments, and that they could clearly locate the source of the punishing event.

The results of Experiments 1 and 2 combined indicate quite remarkable capacities for discriminations in pups as young as 10 days of age. Even though their eyes and ears are not yet open, $10 \mathrm{~d}$ pups demonstrated abilities for locating the mother, learning a choice discrimination, locating the shock, and showing a preference for the dark side of the alley when there was no mother to approach. Although there are several possible explanations for these discriminations (e.g., olfactory, tactile, or thermal cues), the exact basis is presently unclear. The data certainly suggest a variety of learning capabilities in preweanling rats that need to be explored further.

One of the major findings in the present studies is that the younger subjects continued to approach the mother in spite of punishment and regardless of whether they were trained in an alternative response. In addition, there was almost no intersubject variability in 10d pups' behaviors. If adult rats are trained in the same situation and are punished for approaches to food, they linger in the startbox and then retreat to the distant goalbox (Bresnahan et al., 1976). Both $10 \mathrm{~d}$ and $15 \mathrm{~d}$ subjects lingered in the startbox, but both then approached the mother. Fifteen-day subjects sometimes retreated back to the startbox, but not $10 \mathrm{~d}$ subjects. The fact that $10 \mathrm{~d}$ subjects were never observed to exhibit locomotor avoidance while $15 \mathrm{~d}$ subjects did so was the outstanding difference between their behaviors.

We suggest the reason the young pups behave as they do is that all components of retreat and flight reactions are not yet developed by 10 days of age, but are nearly so a few days thereafter. This reasoning is based on the facts that no $10 \mathrm{~d}$ pup was observed to retreat in the first experiment, and that $10 \mathrm{~d}$ pups spent a significantly larger proportion of their time in the startbox punishing area than did the older, 15d pups in the second experiment. Older pups fled to the distant goalboxes and spent all of their time there by 20 days of age.

That 10d pups spent a large amount of their time on the grids in the second experiment might suggest a preference for the grid area as opposed to a lag in the development of the flight reaction. However, after shock trials in the first experiment, younger pups were both slower to leave the startbox area where there were no grids and later stopped in front of the grids before continuing to the mother. Furthermore, differences in locomotion across this floor area cannot account for the behaviors observed following shock trials because both $10 \mathrm{~d}$ and $15 \mathrm{~d}$ pups quickly crossed the grids on their way to the mother before shock was delivered.

Ten-day subjects do not fail in the passive avoidance tasks due to any absolute lack of inhibitory capacities. By 10 days of age, a rat has at least some capacities for passive inhibition, as is clear from the present startbox exit and alley position data, as well as experiments by Amsel, Radek, Graham, and Letz (1977). But the capacity to inhibit does not imply that the young rats can be trained to avoid punishment by retreating from the source of the punishment. This is not because $10 \mathrm{~d}$ subjects cannot run, for they are very good runners so long as they are running toward the mother. Hence, one would think they should also be able to run away from punishment. 
But 10d subjects do not do that and continue their approaches, even when given experience with the alternative alley.

Neither do pups fail the passive avoidance task because of an increase in activity. Such general responding accounts would not predict the linear path data of $10 \mathrm{~d}$ pups, or even the $15 \mathrm{~d}$ pups spending most of their time in the alley containing the mother.

Differences in sensitivity to punishment between the two ages also seem an unlikely possibility to explain the avoidance deficit in 10d pups. If anything, the younger pups may have been more sensitive to the same punishment intensity because their detection thresholds for shock are slightly lower than for the older pups (Collier \& Bolles, Note 2). The findings of the second experiment counter any notions that the results were due to the unconditioned effects of shock alone. Ten-day pups increased the number of paths they took and decreased their startbox exit latencies on shock trials, while $15 \mathrm{~d}$ pups did the opposite. These data show that $10 \mathrm{~d}$ subjects can escape the effects of shock and have the ability to change directions, and that $15 \mathrm{~d}$ subjects have slightly more pronounced capabilities for "freezing." More importantly, the data emphasize the quite discrepant behaviors that are displayed by $10 \mathrm{~d}$ and $15 \mathrm{~d}$ subjects in the shock-alone situation as compared to behaviors when conflict is introduced.

Another possibility may be that systems other than the flight reaction, such as the peripheral visual system, are simultaneously developing in the rat between 10 and 15 days of age and could also be affecting performance. Recent evidence (Hall, Cramer, \& Blass, 1977) indicates that age transitions in suckling behavior are not dependent on visual mediation. Our data suggest this is true for the flight reaction as well. For the $15 \mathrm{~d}$ pups we studied, several still had their eyes closed, and there were no observed differences in the approach, retreat, or flight behaviors between $15 \mathrm{~d}$ pups with eyes open vs. eyes closed. Also, 10d pups with eyes unopened halted in the alley segment in front of the grids in Experiment 1, indicating they could locate the source of punishment without the use of this system. Thus, it is unlikely that the maturation of the visual system alone can account for the differences we found. The potential effects of this and other developing systems on the capacity for flight, however, are certainly topics for future research.

A final alternative argument might be that younger pups behave as they do because they are more strongly attracted to the mother than are the older pups. However, Hall et al. (1977) found that if pups were equally $22 \mathrm{~h}$ deprived, 14- to 15-day-old pups attached to the nipple of an anesthetized mother more quickly than did 9- to 10-day-old pups. In the present studies, measures were taken to attempt to equate for the ap- proach tendencies by means of differential deprivation, holding percentage of body weight loss constant. Furthermore, in the second experiment where there was no mother to approach, and thus no possibly stronger attractant, $10 \mathrm{~d}$ pups displayed strikingly different tendencies toward flight than did $15 \mathrm{~d}$ and older pups. The younger pups spent most of their time near the punishing area, while older pups ran away much sooner, spending most of their time away from the shock area.

Our proposed explanation of a locomotor avoidance deficit also might help to explain what has previously appeared to be inconsistent findings on agedependent effects in the step-down passive avoidance task. Riccio and Schulenburg (1969) studied the behavior of $10 \mathrm{~d}$ and $15 \mathrm{~d}$ pups in such a step-down passive avoidance situation and found that the younger pups initially performed the task better than the older pups. The reason, we believe, is that both $10 \mathrm{~d}$ and 15d pups had capacities for passive inhibition, but the younger lacked a flight reaction which carried the older subjects off the platform.

Finally, we recognize the adaptive significance for younger altricial infants to stay with their mothers, even if the situation becomes stressful. A lag in the development of the flight reaction (as opposed to excitatory tendencies in general) would be one mechanism which would facilitate the younger pups doing so. On these grounds, then, we suggest that approaches and attachments to the mother are a rat's first reaction to pain; that in a conflict situation, such response tendencies override the pups' abilities to respond otherwise; that passive inhibition is next to develop; and that retreat and flight reactions to aversive stimuli come later. If the concept is valid, it may prove to be of considerable importance in predicting what we might expect different aged organisms to learn through the use of aversive controls.

\section{REFERENCE NOTES}

1. Collier, A. C. The ontogeny of response to shock in the neonatal rat pup and its effect on sucking. Paper presented at the meeting of the Eastern Psychological Association, New York, April 1975.

2. Collier, A. C., \& Bolles, R. C. Behavioral response to shock in infant rats. Paper presented at the meeting of the Midwestern Psychological Association, Chicago, May 1976.

\section{REFERENCES}

Amsel, A., Burdette, D. R., \& Letz, R. Appetitive learning, patterned alternation, and extinction in 10-day-old rats with nonlactating suckling as reward. Nature, 1976, 262, 816-818.

Amsel, A., Radek, C. C., Graham, R., \& Letz, R. Ultrasound emission in infant rats as an indicant of arousal during appetitive learning and extinction. Science, 1977, 197, 786-788.

Bresnahan, J. C., Meyer, P. M., Baldwin, R. B., \& Meyer, D. R. Avoidance behavior in rats with lesions in the septum, fornix longus, and amygdala. Physiological Psychology, 1976, 4, 333-340. 
Campgell, B. A., \& Raskin, L. A. Ontogeny of behavioral arousal: The role of environmental stimuli. Journal of Compar. ative and Physiological Psychology, 1978, 92, 176-184.

Camprell, B. A., Riccio, D. C., \& Rohrbaugh, M. Ontogenesis of learning and memory: Research and theory. In M. E. Meyer (Ed.), Second Western Symposium on Learning: Early learning. Bellingham, Wash: Western Washington State College, 1971.

Hall, W. G., Cramer, C. P., \& Blass, E. M. Ontogeny of suckling in rats: Transitions toward adult ingestion. Journal of Comparative and Physiological Psychology, 1977, 91, 1141-1155.

KenNy, J. T., \& Blass, E. M. Suckling as incentive to instrumental learning in preweanling rats. Science, 1977, 196, 898-899.

Maher, B. A., Eldeer, S. T., \& Noblin, C. D. A differential investigation of avoidance reduction versus hypermotility following frontal ablation. Journal of Comparative and Physiological Psychology, 1962, 55, 449.454.

MyERS, J. L. Fundamentals of experimental design (2nd ed.). Boston: Allyn \& Bacon, 1972.
Riccio, D. C., Rohrbaugh, M., \& Hodges, L. A. Developmental aspects of passive and active avoidance learning in rats. Developmental Psychobiology, 1968, 1, 108-111.

Riccio, D. C., \& Schulenburg, C. J. Age-related deficits in acquisition of a passive avoidance response. Canadian Journal of Psychology, 1969, 23, 429-437.

Walters, G. C., \& Grusec, J. E. Punishment. San Francisco: Freeman, 1977.

\section{NOTE}

1. Additional data of our own, as well as published reports by Amsel et al. (1976), indicate that pups under these conditions are not satiated by the criterion trial (approximately 10-15 training trials) and normally continue approaches to the mother.

(Received for publication August 4, 1978; revision accepted January $29,1979$. 